rising to well-defined peaks, the heights of which can be measured with much greater certainty than ordinary step-heights.

With special equipment for very rapid application of potential and oscillographic recording, Matheson and Nichols ${ }^{2}$ and, later, Randles ${ }^{3}$, found peaks on current - voltage curves obtained with normal capillaries. The present results are given by the usual slow rate of application of potential, and no special equipment other than the capillary is required. The investigation is being continued and details will be given elsewhere.

This note is published by permission of the Ministry of Supply and the Controller of H.M. Stationery Office.

Aeronautical Inspection Department,

G. S. SмIтH

Test House,

Harefield, Middlesex.

Sept. 18.

${ }^{2}$ Steghart, F. L., in contribution to a discussion, Analyst, 72,234 (1947).

'Matheson. L. A., and Nichols, N., Trans. Electrochem. Soc., 73, 193 (1938).

' Randles, J. F. B., Trans. Farad. Soc., 44, 322 (1948).

\section{Mercury Photosensitized Reaction of Tetrafluoroethylene}

I HAVE found that the irradiation of tetrafluoro. ethylene in the presence of mercury vapour by light of wave-length $2536 \mathrm{~A}$. causes a mercury photosensitized reaction. The pressure falls and a white powder is formed. A gas of molecular weight $150 \pm 1$, b.p. $-33^{\circ}$ C., m.p. $-80^{\circ}$ C., believed to be hexafluorocyclopropane, molecular weight 150 , b.p. $-31^{\circ} \mathrm{C} .^{1}$, and a small quantity of a mixture of compounds with higher boiling points have been isolated from the products of the reaction. The white powder has properties similar to those of polytetrafluoroethylene $\left(\mathrm{CF}_{2}\right) n^{2}$, the product of the catalysed polymerization of tetrafluoroethylene.

The quantum efficiency of the reaction at various pressures has been measured. At pressures below $10 \mathrm{~cm}$. of mercury, quenching of the mercury fluorescence is not complete, and only very approximate calculations of quantum efficiency can be made. Some of the quantum efficiencies obtained are given in the accompanying table.

$\begin{array}{ccccc}\begin{array}{c}\text { Temperature } \\ \left({ }^{\circ} \mathrm{C} .\right)\end{array} & \begin{array}{c}\text { Initial pressure } \\ \text { (em. mercury) }\end{array} & \begin{array}{c}\text { Light absorbed } \\ \text { (quanta/hr. } \\ \left.\times 10^{-18}\right)\end{array} & \eta_{\mathrm{C}_{3} \mathrm{~F}_{6}} & \varphi_{\mathrm{P}} \\ 29.8 & 10.43 & 1.33 & 0.03 & 0.18 \\ 29.8 & 33 \cdot 61 & 1.38 & 0.32 & 0.30 \\ 29.8 & 8 \cdot 01 & 91 & 0.017 & 0.02 \\ 29.8 & 35.03 & 104 & 0.07 & 0.12 \\ \eta_{\mathrm{C}_{3} \mathrm{~F}_{6}}=\frac{\text { molecules } \mathrm{C}_{3} \mathrm{~F}_{6} \text { formed }}{2 \times \text { quanta absorbed }} ; & \varphi_{\mathrm{P}}=\frac{\text { molecules } \mathrm{C}_{2} \mathrm{~F}_{4} \text { polymerized }}{\text { quanta absorbed }}\end{array}$

The quantum efficiency of hexafluorocyclopropane production increases with increasing pressure and decreases with increasing intensity. As this compound is the main product, one of the primary reactions must involve the breaking of a carbon-carbon bond. The formation of a polymer indicates the presence of free radicals in the system, and the decrease of efficiency of perfluorocyclopropane production with increasing intensity can be accounted for only by a radical recombination reaction. The results obtained are in accord with the following reaction scheme.

$$
\begin{aligned}
\mathrm{C}_{2} \mathrm{~F}_{4}+\mathrm{Hg}\left({ }^{3} \mathrm{P}_{1}\right) & =2 \mathrm{CF}_{2}+\mathrm{Hg}\left({ }^{1} \mathrm{~S}_{0}\right) ; \\
\mathrm{CF}_{2}+\mathrm{C}_{2} \mathrm{~F}_{4} & =\mathrm{C}_{3} \mathrm{~F}_{6} ; \\
2 \mathrm{CF}_{2}+\mathrm{C}_{2} \mathrm{~F}_{4} & =2 \mathrm{C}_{2} \mathrm{~F}_{4} ; \\
\mathrm{CF}_{2}+\mathrm{CF}_{2} & =\mathrm{C}_{2} \mathrm{~F}_{4} \text { (at the walls). }
\end{aligned}
$$

Reaction (2) is probably the reaction initiating polymer formation.

A surprising feature of the reaction is that the $112 \mathrm{k} . c a l$. per $\mathrm{gm}$. mol. available from the excited mercury atoms is sufficient to cause the carboncarbon bond to break. The bond-energy of the double bond in ethylene is stated to be 153 k.cal. per gm. mol. ${ }^{3}$ If the double bond in tetrafluoroethylene has about the same bond-energy, reaction (I) can take place only if the bond-energy of the carbonfluorine bond in the difluoro-methylene radical is approximately $10 \mathrm{k} . c a l$. higher than the corresponding bond-energy in tetrafluoroethylene. The reaction of tetrafluoroethylene may be contrasted with the mercury-photosensitized reaction of ethylene, in which acetylene and hydrogen are the primary products 4

Department of Inorganic and

B. Atrinson

Physical Chemistry,

Imperial College of Science and Technology, London, S.W.7.

Oct. 1.

1 Harmon, J., U.S. Patent 2,404,374 (1946)

2 Renfrew, M. M., and Lewis, E. E., Indust. Eng. Chem., 28, 870 (1946).

${ }^{3}$ Walsh, A. D., Trans. Farad. Soc., 42, 779 (1946).

4 Le Roy, D. J., and Steacie, E. W. R., J. Chem. Phys., 9, 829 (1941).

\section{An Outline of a Theory of Detonators}

Further to the reported property of silver formate of detonating at $85-90^{\circ}$, it is perhaps opportune to offer some commentary on the nature of detonators in general. They are commonly derived from acids, the anions of which are the repositories of considerable stores of energy. This is liberated when the anions are discharged and the radicals, thus initially produced, decompose. Anodic discharge from aqueous solution is obviously one method of achieving this, and Audubert has recorded that such discharge of the azide ion is accompanied by liberation of light energy ${ }^{2}$. Another mode of discharge, illustrative of the possible application of these ideas to the picrates, is represented by the action of lead tetracetate on various paranitrophenoxide ions, leading to their decomposition into nitric oxide and paraquinone ${ }^{3}$. In detonators, such anions are associated with heavy metallic cations in what may be approximately de. scribed as covalent union ${ }^{4}$, and this constitutes a stage in the transition from the fully charged anion to the unstable radical. The process of transition is completed by a suitable supply of energy in the form of a blow, heat or otherwise, and this stage is illustrated by the historic thermal decompositions of mercuric oxide and cyanide and by that of silver salts of carboxylic acids. Local decomposition of this kind in a mass of the detonator will liberate energy, which on communication to immediately adjoining material will cause further decomposition leading to detonation.

Regarding individual detonators, the fulminate ion $(\mathrm{CNO})^{\prime}$, derives its energy from the abnormal arrangement of its atoms, as is clear from the fact that oxidation of cyanide ion yields cyanate ion $(\mathrm{OCN})^{\prime}$. The fulminate ion, like the azide, formate and picrate ions, is stabilized by resonance; but the 